\title{
DEFENDER A ESCOLA DO DISPOSITIVO PEDAGÓGICO: O LUGAR DO EXPERIMENTUM SCHOLAE NA BUSCA DE OUTRO EQUIPAMENTO COLETIVO
}

\author{
IN DEFENCE OF THE SCHOOL AGAINST THE PEDAGOGICAL DISPOSITIVE: \\ THE PLACE OF EXPERIMENTUM SCHOLAE TO REACH OTHER COLLECTIVE \\ EQUIPMENT
}

\begin{abstract}
DEFENDER LA ESCUELA DEL DISPOSITIVO PEDAGÓGICO: EL LUGAR DEL EXPERIMENTUM SCHOLAE EN BUSQUEDA DE ÓTRO EQUIPAMIENTO COLECTIVO
\end{abstract}

Alexandre Filordi de Carvalho'; Silvio Donizetti de Oliveira Gallo ${ }^{2}$

\begin{abstract}
RESUMO
É preciso defender a escola. De quê? De quem? Neste texto, partiremos da noção de "dispositivo pedagógico", elaborada pelo filósofo René Schérer, para fazer da escola o principal combatente contra a forma que ela mesma assumiu institucionalmente na modernidade, catalisada por este dispositivo. Em obra de 1974 Schérer afirmava que não basta a crítica à escola, não bastam os projetos de "desescolarizar a sociedade" (Illich), uma vez que aquilo que funciona em nosso tempo é uma intrincada "ideologia pedagógica". Ela sim é que deve ser combatida. Após os trabalhos de Foucault que introduziram o conceito de dispositivo, Schérer passou a tratar a questão em termos de um "dispositivo pedagógico" que coloniza nossa sociedade segundo a forma de uma pedagogização integral, na direção daquilo que Rancière denominou uma "sociedade pedagogizada". 0 combate, então, direciona-se contra este dispositivo que pedagogiza, impedindo os processos de autoformação. Após elucidar o conceito de dispositivo pedagógico, buscaremos na noção guattariana de "equipamentos coletivos" possibilidades de repensar a escola como máquina de guerra em ação contra o dispositivo pedagógico. Ainda que a própria escola enredada pelo dispositivo pedagógico seja um equipamento coletivo, o equipamento coletivo pode ser pensado de outra maneira, visando a defender a escola do dispositivo pedagógico. Ao cabo, trata-se de defender a escola como experiência de um outro equipamento coletivo, como um experimentum scholae.
\end{abstract}

PALAVRAS-CHAVE: Dispositivo pedagógico. Escola. Equipamento coletivo. Poder. Experimentum scholae.

\begin{abstract}
The school must be defended. From what? From who? In this text, we will start from the notion of "pedagogical dispositive", elaborated by the French philosopher René Schérer, to make of the school the main combatant against the form that it herself assumed institutionally in the modernity, catalyzed by this dispositive. In 1974 Schérer's work argued that is not enough criticism to school, nether the projects of "deschooling society" (Illich), because what is working in our time is an intricate "pedagogical ideology". It is this ideology that must be fought. After the work of Foucault, who introduced the concept of dispositive, Schérer came to discuss that issue in terms of a "pedagogical dispositive" that colonizes our society in terms of an integral pedagogization toward what Rancière called a 'pedagogized society. The fight then is directed against this dispositive that pedagogizes, preventing self-formation processes. After elucidating the concept of

\footnotetext{
${ }^{1}$ Doutor em Educação - Universidade Estadual de Campinas (UNICAMP) - Campinas, SP - Brasil. Graduado em Pedagogia - Universidade Estadual de Campinas (UNICAMP) - Campinas, SP - Brasil. Professor em Educação Universidade Federal de São Paulo (UNIFESP) - São Paulo, SP - Brasil. E-mail: afilordi@gmail.com

2 Doutor em Educação - Universidade Estadual de Campinas (UNICAMP) - Campinas, SP - Brasil. Graduado em Filosofia - Pontifícia Universidade Católica (PUCCAMP) - Campinas, SP - Brasil. Professor em Educação Universidade Estadual de Campinas (UNICAMP) - Campinas, SP - Brasil. E-mail: silvio.gallo@gmail.com
} 
pedagogical dispositive, we will seek in the guattarian notion of "collective equipment" possibilities of rethinking the school as a war machine actioning against the pedagogical dispositive. Although the school is entangled by the pedagogical dispositive making itself a collective equipment, the collective equipment can be thought of another way, aiming to defend the school from the "pedagogical dispositive." In the end, it is about defending the school as an experience of other collective equipment, such as well an experimentum scholae.

KEYWORDS: Pedagogical dispositive. Collective equipment. School. Power. Experimentum scholae.

\section{RESUMEN}

Hace falta defender la escuela. ¿De qué? ¿De quién? En este texto, se parte de la noción de "dispositivo pedagógico", creada por el filósofo francés René Schérer, para hacer de la escuela el principal combatiente contra la forma que ella asumió institucionalmente en la modernidad, catalizada por este dispositivo. En 1974 el trabajo de Schérer sostenía que no es suficiente la crítica a la escuela, y que no son suficientes los proyectos para "desescolarizar la sociedad" (Illich), ya que lo que funciona en nuestro tiempo es una intrincada "ideología pedagógica". Después, con la introducción, por Michel Foucault, del concepto de dispositivo, Schérer pasó a discutir la cuestión en términos de un "dispositivo pedagógico" que coloniza nuestra sociedad bajo la forma de una pedagogización total, hacia lo que Rancière llama una "sociedad pedagogizada". La lucha entonces se dirige contra este dispositivo que pedagogiza, bloqueando los procesos de auto-formación. Después de aclarar el concepto de dispositivo pedagógico, se busca en la noción de Guattari llamada equipamiento colectivo una forma de repensarse la escuela como una máquina de guerra en acción contra el dispositivo pedagógico. Aunque la escuela tramada en el dispositivo pedagógico sea también un equipamiento colectivo, el equipamiento colectivo puede ser pensado de manera distinta, intentando defender la escuela del dispositivo pedagógico. Al final, se trata de defender la escuela como experiencia de un otro equipamiento colectivo, como un experimentum scholae.

PALABRAS CLAVE: Dispositivo pedagógico. Equipamiento colectivo. Escuela. Poder. Experimentum scholae

\section{QUESTÕES INICIAIS}

Hilsdorf (2006) apresenta como uma espécie de "certidão de nascimento" da escola moderna o aparecimento dos "colégios de humanidades" no século XVI, herdeiros da tradição dos mestres humanistas dos séculos XIV e XV. Tais instituições foram as primeiras a romper com as perspectivas teocêntricas medievais e com o currículo praticado nas universidades, baseado no trivium e no quadrivium, inaugurando um ensino orientado pelo movimento humanista e centrado no estudo das letras clássicas, com grande ênfase no latim. Começaram aí a organização das etapas do ensino e o agrupamento de alunos que estudavam os mesmos conteúdos. A autora chega a traçar uma linha genealógica que liga os colégios de humanidades às instituições escolares dos calvinistas e dos jesuítas (2006, p. 72).

Não é nosso objetivo aqui fazer a genealogia da escola moderna, mas apenas assinalar que a instituição escolar vai sendo constituída pouco a pouco, com o encontro de diferentes fluxos e experiências, de distintas proveniências, que vão dando forma a esta maquinaria escolar que hoje conhecemos. A escola que hoje habitamos não é certamente a mesma dos séculos anteriores, mas ela foi sendo forjada nestes fluxos. Um deles, importante de ser destacado, foi analisado em intensidade por Foucault (1991) em Vigiar e

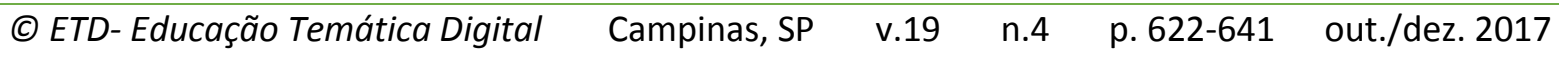


Punir, empenhado em destacar os elementos constitutivos do poder disciplinar. A escola foi lugar de experimentação e de consolidação da disciplina, apresentando efeitos positivos e muito produtivos. Na perspectiva de Foucault, sabemos, a disciplina é a base do capitalismo. Não foi pouco o que ela produziu, portanto. Mas também a disciplina produziu uma conformação subjetiva do ser humano moderno, desempenhando a escola papel fundamental em tal processo.

A partir do século XIX, no reboque das revoluções burguesas na Europa e na América, os sistemas públicos de ensino vão sendo constituídos, consolidando uma formaescola que perdura até este início de século XXI. Transformações ocorreram, obviamente, mas, em boa medida, a instituição escolar está consolidada e todos conhecemos bem seus rostos e seus efeitos, suas produções materiais e suas produções subjetivas.

Masschelein e Simons (2013) apontam para a necessidade de se "defender a escola" como uma questão pública. Mas defendê-la de quê? Das forças sociais e políticas contemporâneas que corroem cada vez mais seu sentido originário, de uma interrupção no tempo produtivo, que possibilita experiências formativas. Fora do seio da família e ainda não totalmente inseridas no âmbito social da produção, crianças e jovens podem experimentar o mundo e formarem-se. Mas quando os processos formativos são direcionados pelos interesses estritos do Estado, como, por exemplo, uma formação visando a preparação para o trabalho, conjugada com uma formação para a cidadania, ${ }^{3}$ para ficarmos no caso brasileiro, que nos toca diretamente, perde-se o sentido da escola como "tempo livre", um tempo do qual o sujeito pode dispor conforme seus interesses próprios, absolutamente necessário para sua constituição subjetiva.

O curioso, precisamos ressaltar, é que tudo isso se coloca num tempo e num mundo em que a escola nunca foi tão central. Uma sociedade que Rancière (2002) não hesitou em chamar de "sociedade pedagogizada", visto que nela parte-se do princípio de que alguém só aprende quando um outro (o mestre) ensina, gerando uma hierarquização na aquisição e na relação com os saberes que impossibilitam uma efetiva emancipação intelectual. Impõe-se então a pergunta: numa sociedade pedagogizada, por que a escola precisa ser defendida, posto que ela parece ser uma instituição central? $\mathrm{E}$, mais do que isso: se a escola precisa ser defendida, defendida de quem e do quê?

\footnotetext{
${ }^{3}$ Interessante destacar que ainda em 1874, quando publicou Schopenhauer Educador, Nietzsche fez a crítica de uma educação voltada a um fim específico, que ele chamou de "egoísmo", destacando, por exemplo, o "egoísmo dos negociantes", que visam uma formação voltada para o comércio e o "egoísmo do Estado, que visa uma educação para formar os quadros para o funcionalismo público. Ver: Nietzsche, 2003, p. 185 e ss.
}

\begin{tabular}{|c|c|}
\hline$a D$ & $n 4$ \\
\hline
\end{tabular}


Neste artigo, exploraremos uma hipótese, na companhia do filósofo René Schérer: para além da escola, constitui-se na modernidade um "dispositivo pedagógico" que primeiro "pedagogizou" a escola e depois estendeu seus tentáculos, "pedagogizando" a teia social, ao menos, desde o século XVIII. A força de tal dispositivo é tamanha, que não importa o que façamos com a escola, ele segue atuando. Mesmo frente a uma "desescolarização" da sociedade, seguindo a proposta de Illich (1982), o dispositivo pedagógico se entranharia em outras instituições, mantendo a pedagogização operante. Nossa hipótese, pois, é que a escola precisa ser defendida de um tal dispositivo; para isso, pensaremos com Félix Guattari a escola como outro tipo de equipamento coletivo, na contramão do dispositivo pedagógico, para tentar alcançar o que Masschelein e Simons (2013) pensam acerca do experimentum scholae.

\title{
Schérer e o dispositivo pedagógico
}

Segundo Schérer (2009), a modernidade produziu "utopias pedagógicas" que buscam reformas sociais pela educação, criando máquinas político-educativas: as escolas. Na utopia, política e pedagogia se aliançam:

\begin{abstract}
As massas constituem uma matéria resistente para a ação política, cuja tarefa consistirá, portanto, em educá-las. Duplo princípio, que orienta o círculo vicioso do poder, que designo como utopia pedagógica, quer dizer, a ideia de uma reforma social pela educação, a ideia de que seria possível formar um homem capaz de construir uma sociedade mais bem instruída - ou um homem mais bem-dotado, capaz de construir uma sociedade diferente. Assim a utopia pedagógica é apenas outra face da utopia política que, por sua vez, está sempre não só acompanhada por pedagogia, mas ela própria é pedagógica; eis o que, aliás, já sabemos desde Platão. (SCHÉRER, 2009, p. 26)
\end{abstract}

Schérer corrobora a ideia que apresentamos anteriormente, de que a partir do século XIX, sob a herança das pretensões iluministas do século anterior, consolida-se a escola em sua feição moderna; e ele acrescenta: tal escola apresenta sua face utópica:

Desde o século XIX, o sistema escolar e os professores primários foram os paladinos da transformação da sociedade pela educação. A escola libertadora, a da igualdade de oportunidades, da República, da laicidade e do povo, tudo isso levou a esquecer a maneira como a máquina do poder havia conseguido sua cabal instalação! (SCHÉRER, 2009, p. 27)

Pedagogia e utopia, pois, como exercícios de poder que se materializam no jogo social, produzindo uma determinada sociedade, segundo princípios julgados estruturantes.

Tanto as pedagogias oficiais, institucionalizadas em escolas, como as diferentes utopias pedagógicas, que planejam uma nova institucionalização em uma nova escola, estão marcadas por uma perversão pedagógica: educamos para conformar as crianças a um dado padrão social. Inventamos uma infância e enquadramos a criança nesta categoria, de modo que ela precisa ser conduzida (eis aí o papel da pedagogia) à vida adulta.

\begin{tabular}{|c|c|}
\hline - Educacão Temática Diqital & Comni \\
\hline
\end{tabular}


Em 1974 Schérer publicou aquela que seria, a nosso ver, uma das mais duras críticas à educação moderna: Émile Perverti (numa tradução literal, o título em português seria "Emílio Pervertido"). Não por acaso, Schérer toma por ícone o personagem criado por Rousseau para retratar o processo educativo e de formação subjetiva de uma criança, do nascimento à idade adulta. Se com seu Emílio o filósofo genebrino lançou as bases de muito do que seria a educação nos séculos seguintes, é sobre ele que Schérer se volta para fazer a crítica do que se tornou essa educação no mundo contemporâneo. Em breves palavras visto que este não é o centro de nossas preocupações neste artigo - o filósofo francês mostra que o "mundo natural" no qual Rousseau educa Emílio é, de fato, um panorama artificial, criado pelo pedagogo para controlar o desenvolvimento da criança. Não se trata, pois, de um desenvolvimento "em liberdade" e "de acordo com a natureza", mas de um experimento controlado, e muito bem controlado, que conduz a uma formação desejada. Segundo Schérer, Rousseau antecipa a noção de panóptico proposta depois por Bentham e que Foucault analisa em Vigiar e Punir, como tecnologia de controle visual, uma vez que todo o processo educativo se dá "sob o olhar do mestre", que controla o percurso e mesmo os possíveis desvios.

Um elemento central na obra de Schérer, mas que também foge de nossas intenções neste texto, é a afirmação de que a perversão pedagógica da infância diz respeito a uma negação da sexualidade infantil, ou sob os auspícios da psicanálise, seu reconhecimento e confinamento no familialismo através da afirmação do complexo de Édipo. A perversão, pois, não é educar sexualmente a criança, é simplesmente fingir que a criança é um ser assexuado, que não é um ser de desejo.

Postas estas questões de fundo do pensamento do autor, que não desenvolveremos aqui, chegamos àquele que é nosso ponto de interesse: na obra de 1974, Schérer afirma a existência de uma "ideologia pedagógica", que está para além da escola e dos sistemas educativos. Seria tal "ideologia pedagógica" que maquinaria os processos educativos modernos e contemporâneos, conformando a instituição escolar segundo seus princípios. De forma que não adianta criticar a escola ou mesmo revoltar-se contra ela, reivindicando sua destruição, seu desaparecimento: a "ideologia pedagógica" permaneceria em ação, talvez ainda mais forte, ao diluir-se pela malha social.

Não é apenas a escola contemporânea, com seu imenso aparelho administrativo, que está em jogo [...] A luta contra a escola-instituição é boa, mas é necessário retornar, através dela, ao cerne do discurso inaugural no qual ela se justifica que, não sendo estritamente escolar, é muito mais pedagógico. Através da escola, é a ideologia pedagógica no seu conjunto que precisa ser visada, ainda que os ridículos retardados da instituição façam com que talvez os pedagogos se rebelem contra ela em nome de um ideal que ela apenas traiu. (SCHÉRER, 2006, p. 21-22). 
A questão que Schérer faz descortinar aos nossos olhos, pois, é: quando criticamos a educação moderna, nosso alvo não deve ser a escola. Esta instituição é uma importante peça nesta maquinaria, mas não é a peça decisiva, não é seu "coração"; não basta destruirmos a escola, a maquinaria seguiria em funcionamento, pois a "ideologia pedagógica" reorganizaria os elementos que a compõem para seguir funcionando normalmente. ${ }^{4}$ Mas uma ressalva é importante. Ainda que utilize a expressão "ideologia pedagógica", é de uma materialidade que Schérer está tratando; nada mais equivocado do que compreender essa ideologia no sentido "clássico" marxista, como falseamento do real. O filósofo está falando de um real, de uma organização material dos processos pedagógicos permeando as instituições e as relações. Uma concepção de mundo, em sentido amplo, mas que só faz sentido quando "se faz carne", só faz sentido porque é o mundo, não a sua representação.

Percebemos, assim, que a expressão "ideologia pedagógica" não faz jus à complexidade pensada por Schérer. Quando, em 1976, Foucault publicou o primeiro volume de sua História da Sexualidade - a vontade de saber, apresentou o conceito de dispositivo de sexualidade, uma trama complexa de materialidades e de relações que fazem da sexualidade um dispositivo de saber-poder. Para melhor compreender essa noção de dispositivo, fiquemos com uma exposição condensada feita pelo próprio Foucault:

O que eu tento descobrir sob esse nome é, primeiramente, um conjunto decididamente heterogêneo, que comporta discursos, instituições, arranjos arquitetônicos, decisões regulamentares, leis, medidas administrativas, enunciados científicos, proposições filosóficas, morais, filantrópicas, em resumo: do dito, tanto quanto do não dito, eis os elementos do dispositivo. O dispositivo propriamente é a rede que se pode estabelecer entre esses elementos.

Em segundo lugar, o que gostaria de descobrir no dispositivo é exatamente a natureza do laço que pode existir entre esses elementos heterogêneos [...] Em terceiro lugar, por dispositivo entendo uma espécie - digamos - de formação, que, em um dado momento histórico, teve por função maior responder a uma urgência. O dispositivo tem, pois, uma função estratégica dominante. (FOUCAULT, 2014, p. 45).

$\mathrm{Na}$ esteira de Foucault, Schérer passou a afirmar a existência de um dispositivo pedagógico: um conjunto heterogêneo, disposto na forma de uma rede, que engloba discursos e pensamentos, mas também instituições e arquiteturas, leis e ações de administração, proposições filosóficas e verdades científicas, máximas morais e religiosas.

\footnotetext{
${ }^{4}$ Parece-nos importante ressaltar que essa perspectiva teórica de Schérer aproxima-se de modo interessante daquela que Rancière apresentaria pouco mais de uma década depois em Le Maître Ignorant, cuja publicação original é de 1987, ao fazer a crítica da sociedade pedagogizada. Ainda que a perspectiva de Rancière diga respeito ao método de explicação - este é o foco de sua crítica - ele ressalta que tal método fundamenta o processo de pedagogização de toda a sociedade moderna. Chamamos a atenção do leitor para o fato de que a análise de Rancière não menciona "ideologia", ainda que ele tenha sido discípulo de Althusser. Sua análise destaca, ao contrário, a materialidade da sociedade pedagogizada.
} 
Segundo Foucault (2014, p. 45-46), o dispositivo dá coesão a essa rede de elementos. Ele possui também uma função estratégica, responde a uma problemática que emerge numa determinada época histórica, constituindo-se como uma formação: discursiva, legal, administrativa, epistêmica, moral etc. Enfim, o dispositivo desenha e possibilita um jogo de poder entre seus vários elementos e os sujeitos nele implicados.

Nesse sentido, o próprio Schérer esclareceu o que entende por dispositivo pedagógico:

\begin{abstract}
A colocação em funcionamento de um observatório, o estabelecimento de um terreno artificial de observação dos fatos e dos gestos da criança na sua integralidade. É a descrição das relações, em Rousseau, entre Emílio e o preceptor, que parece-me ser o esquema mais claro. Pois Emílio exemplifica o dispositivo da "educação negativa", que consiste em deixar a criança livre para se desenvolver, mas nas condições de um meio previamente reservado pelo pedagogo. Rousseau insiste: o perigo vem sempre de fora. Por isso intitulei meu primeiro livro sobre a infância Emílio pervertido. (SCHÉRER; LAGASNERIE, 2007, p. 149-150).
\end{abstract}

E a dessexualização da infância, que criminaliza como pedofilia qualquer gesto ou toque do adulto em relação à criança, ${ }^{5}$ é evidenciada por ele como o centro deste dispositivo, como esclarece no prefácio à segunda edição (2006) de Émile Perverti:

O centro de nosso sistema, de nosso "dispositivo" pedagógico, como dizia Michel Foucault, em relação à infância, é certamente essa distância exigida, essa criminalização em proporções desmedidas, inéditas, de qualquer gesto, de qualquer toque. (SCHÉRER, 2006, p. 10).

A partir da leitura de René Schérer, podemos dizer que o elemento de coesão do dispositivo pedagógico é justamente a perversão. Perverter a criança, conformá-la à visão dos adultos, num ser inocente e assexuado é aquilo que une as várias linhas de forças materiais e imateriais deste dispositivo.

É nesse contexto que se pode afirmar que a criança moderna é definida por uma "pedagogização integral", que ela não pode ser compreendida senão como objeto de processos educativos. É o dispositivo pedagógico que infantiliza, que transforma a criança na viva expressão de um conceito inventado pelos adultos. $E$, além disso, seria inútil

\footnotetext{
${ }^{5} \mathrm{Na}$ cultura francesa, em que o toque corporal não é tão comum como entre nós, Schérer afirma que qualquer toque do adulto numa criança pode ser interpretado como intenção erótica do adulto, visto que a criança é "dessexualizada". Talvez no Brasil as coisas não sejam assim tão rígidas. Mas, não podemos deixar de notar que com a recente publicação da última versão da Base Nacional Curricular Comum para o Ensino Fundamental eliminou todas as referências a orientação sexual e a questões de gênero. Que será isto senão um reforço na dessexualização da infância, um investimento na perversão pedagógica denunciada por Schérer?
} 
defender, por exemplo, uma "desescolarização"; ${ }^{6}$ o dispositivo pedagógico está de tal modo espalhado pelo sistema social, que a pedagogização integral não deixaria de atuar, entranhando-se em outras instituições que não a escola, para continuar desempenhando seu papel de infantilização.

Para enfrentar tais questões recorreremos a Guattari, que nos incita a pensar a escola como equipamento coletivo. Mas para tanto, é preciso partir da concepção de que a própria escola é um equipamento coletivo conformado ao dispositivo pedagógico, gerando perversões na educação. Colocar tal dimensão em xeque é, ao mesmo tempo, defender a escola do dispositivo pedagógico, a fim de alcançarmos, a partir da própria escola, um outro tipo de experiência tanto escolar como de formação.

Escola e equipamento coletivo: em busca de outro experimentum scholae

Para enfrentarmos a perversão pedagógica arraigada na escola contemporânea é interessante partir do preciso diagnóstico de Schérer (2009, p.28): "a escola limita-se a ocultar o que ela é de fato: máquina de poder". Já sabemos que não é em termos ideológicos, contudo, espécie de realidade invertida e eivada de uma falsificação fantasmagórica, que devemos ter em mente tal assertiva. O ocultar da escola é um tipo de lance mágico, regra própria do dispositivo pedagógico, a operar um jogo de evidência que, a bem da verdade, insiste em apostar nas regras capazes de invalidar a sua mais cruel evidência, ou seja, que antes de atingir a sua finalidade precípua de herança pretensamente iluminista, a fim de cumprir com um projeto de instrução,

a escola produz indivíduos dóceis e comportamentos sociais irreversíveis diante dos detentores do "saber", além de justificar a hierarquia e de legitimar a força pregnante de certas instituições, tais como a família nuclear que é requisitada, essencialmente, em razão da escola, para vigiar a criança, responsabilizando-se por seu sustento e sua assiduidade na aprendizagem. (SCHÉRER, 2009, p.29).

Não é para aprender que se vai à escola como causa primeira. Mas para cumprir o ritual inicial, incessante litania de passagens, junto com as regras familiares, visando a inserção de seus sujeitos na máquina de poder. Visibilidade tão escandalosa que insiste a ser negada, afinal de contas, quem haveria de se lançar contrário à escola e aos seus preciosos passes de inserção civilizatória? Uma vez, porém, que o dispositivo pedagógico se faz um com a máquina de poder, não é apenas o conjunto todo montado da escola, espécie de grande máquina, que passa a ser questionada. Questionar a escola é forçosamente

\footnotetext{
${ }^{6}$ A primeira edição de Émile Perverti foi publicada numa época em que as teses apresentadas por Ivan Illich no livro Sociedade sem Escolas, publicado originariamente em 1971, eram bastante comentadas. Schérer procura mostrar que, frente à força do dispositivo pedagógico, essas teses são inócuas. Em suas palavras, a luta contra a escolarização absoluta é boa, mas não suficiente; é preciso ir além da crítica à escola, criticando a pedagogização da sociedade.
}

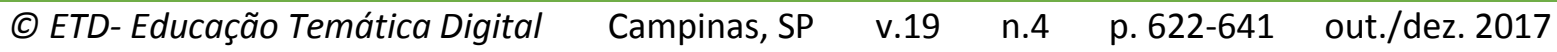


colocar em questão o seu dispositivo pedagógico e, claro está, todo o seu alcance social, com o intuito de defendê-la deste dispositivo.

Sendo assim, podemos argumentar que a escola é uma máquina de poder que coloca em operação o dispositivo pedagógico. E é precisamente isto que a escola, de modo mágico, insiste em "ocultar". Com efeito, convém-nos também olhar para as pequenas correias de transmissão de poder presentes no dispositivo pedagógico, para os seus pequenos fios de conexões que o mantêm no mesmo enérgico funcionamento, e para uma miríade de engrenagens a dar sentido aos seus fluxos de formação perversos. Colocado deste modo, defender a escola também seria defendê-la de um tipo de máquina de poder, ou seja, da máquina produtora do dispositivo pedagógico perverso. Se tratamos, porém, de defender a escola das operações desta máquina de poder, não podemos nos furtar a pensar algum tipo de ação que se volte para o desmonte de tal máquina, peça por peça, engrenagem por engrenagem. Assim, tentaríamos abrir novos espaços de dentro de sua maquinaria para que a escola possa, por meio de outra configuração, operar fluxos de relações distintos aos quais estamos habituados nela a convi(ver). Tratar-se-iam de fluxos capazes de potencializar para os seus sujeitos uma produção de experiências criativas, originais, destronadas dos controles da hierarquia sórdida e, por vezes, sádica; fluxos de relações de um poder antiprodutivo no que diz respeito às regras estanques da burocracia curricular, conteudista e cínica, a ponto de ignorar o terreno fértil dos afetos como lugar possível da aprendizagem, do conhecimento e do saber.

Uma dupla localização desta máquina de poder, contudo, deve ser empreendida. Em um nível, o dispositivo pedagógico encontra-se conectado aos fios das engrenagens de uma espécie de extensa conveniência de coerência fundante, grosso modo disseminada na formação geral da escola moderna. De outro lado, o dispositivo pedagógico, como máquina de poder, também se especializa nas minúcias dos particularismos de cada escola, justamente pelo fato de que a máquina de poder não existe e não pode funcionar sem um equipamento coletivo. Analisemos melhor tais aspectos.

No primeiro caso, isto é, atinente à grande extensão da máquina de poder da escola, sabemos que o século XVIII configura o período histórico das grandes fundamentações teóricas e dos arranjos empíricos ao redor da escolarização da infância (ENGUITA, 1989; GÉLIS, 2009; SCHÉRER, 2009). Menos ainda que a disseminação do confisco da infância marginal por intermédio dos orfanatos, das workhouses e das oficinas preparatórias de uma educação que se tornasse um "meio de adquirir ou instilar o hábito da laboriosidade", como sustentava William Powell em 1772, conforme analisa Enguita (1989, p.114), o século XVIII foi lugar da emersão da engrenagem vital do funcionamento da máquina escolar moderna, pelo fato de que o Estado passou a tomar o encargo do sistema educativo. Em tal conjuntura e desde então, na interpretação de Gélis (2009), dissolveu-se o espaço da 
afetividade para ceder lugar à integração social da criança, cujas aptidões deveriam ser consoantes à uma ordem pública de interesses sob os quais o afeto não poderia mais ser um obstáculo para a sua realização.

Remarcar tais aspectos, embora de amplo conhecimento no campo da educação, é de todo modo importante porque, conforme expõe Schérer (2009), o dispositivo pedagógico garantiu a sua universalização com o espírito do século XVIII. Poderíamos até argumentar que a escola, como a conhecemos e se articula para ser máquina de poder, ainda não se desconectou das grandes representações idealizadas para ela a partir século XVIII. Para Schérer, Rousseau, Kant e Bentham coadunam a força de reatualização do dispositivo pedagógico, forjado para se vingar universalmente.

No caso de Rousseau, apesar de toda crítica que o filósofo iluminista fez aos "estabelecimentos ridículos a que chamam colégio" (ROUSSEAU, 1992, p.14), foi a representação de homem natural, sempre destinado aos arranjos artificiais de uma formação a ser controlada em todos os seus aspectos, como vemos na proposta de Emílio, que passou a configurar uma das correias de transmissão necessárias ao dispositivo pedagógico. A suposição de que "na ordem natural, sendo os homens todos iguais, sua vocação comum é o estado de homem" (ROUSSEAU, 1992, p.15), fez do dispositivo pedagógico uma arma de fazer encaixar idealização natural com concepção de homem. Dito de outro modo, Rousseau precisou forjar uma concepção universal de homem para maquinar formas e estratégias de modelagem da infância visando à extração de um homem dotado de signos reprodutíveis ad infinitum. Quer dizer que, a despeito de ser para Rousseau (1992) a educação menos preceitos do que exercícios, na realidade, ele não abriu mão do preceito da existência de uma ordem natural que deveria ser mantida em cativeiro no próprio homem idealizado. A sua extração, contudo, não ocorreria senão por exercícios, isto é, por experiências artificiais ao próprio homem, cujo Emílio não deixaria de ser um manual prático a ser observado. É desta maneira que a infância passou a ser capturada pelo dispositivo pedagógico. Este, por sua vez, foi reduplicado em progressão geométrica, já que é desde a infância que o homem passou a ser evocado: homem universal, essencializado ex pueris excessit, duplamente vinculado ao dispositivo da pedagogia perversa, ou seja, na criança há de se prever o homem a ser alcançado, e no homem a criança que ele jamais deverá abandonar, voltando-se sempre à sua ordem natural adâmica. Com efeito, e a partir de então, "a criança só é o objeto predileto do pedagogo por ser o homem, finalmente, tornado visível. Mas essa compulsão ao ver é também o que sustenta o projeto infinito de uma dominação estatal sobre toda a vida, inclusive, intelectual". (SCHÉRER, 2009, p.33).

Ora, foi em Kant e em Bentham, entretanto, que as regras da visibilidade pedagógica alcançaram uma dupla especialização. Em uma via, com Kant, a especialização da visibilidade de regras claras para a composição de uma pedagogia especializada em

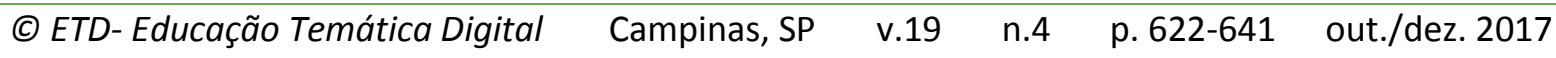


fundamentos assentados em princípios racionais. Com Bentham, a via da especialização tecnocrática dos espaços aplicados à ordem escolar, para melhor fazer funcionar a sua máquina de poder.

A partir de 1776, com as conferências de Kant Sobre a pedagogia (2011), temos um marcador histórico-filosófico interessante, responsável por conceber a educação como a tríplice tarefa de cuidado da infância, de sua disciplina e de sua instrução. Para tanto, foi necessário definir a pedagogia como a arte da educação raciocinada. As dimensões moral, estética e racional deveriam estar presentes na composição de tal campo pedagógico. Kant levava em consideração o seu projeto idealista de sociedade perfeita, cujo esboço seria assumido por indivíduos capazes de se adequarem à ordem privada da razão do Estado, não ultrapassando os limites de suas funções e das margens do uso de suas liberdades afinadas ao consenso mútuo cujo fiel da balança haveria de ser o constante equilíbrio entre o uso privado e o uso público da razão.

Esta ambição, contudo, tornou-se universal, já que o objetivo ulterior da educação passou a ser o de ensinar aos homens, desde a infância disciplinada e instruída, a formarem por si mesmos os projetos de suas condutas. Por isso mesmo, Kant não abria mão de seu preceito: "Quanto tempo deve durar a educação? Até o momento em que a natureza determinou que o homem governe a si mesmo" (2011, p.32). Mas qual seria o indicativo desta natureza que clama pela imposição do autodomínio do homem, no sentido de um projeto civilizatório? Kant (2011, p.32) responde: “[...] até que nele [no homem] se desenvolva o instinto sexual; até que ele possa tornar-se pai e seja obrigado, por sua vez, a educar".

Kant inventou a abertura de um ciclo que se fecha em si mesmo. A infância é manejada sob o efeito de uma pedagogia raciocinada pois deve ser previsível, calculada, visando a eficiência qualificada sob as demandas repetíveis do Estado, ou seja, conforme a sua burocracia. Podemos pensar que Kant efetivamente institucionalizou o dispositivo pedagógico no âmbito da demanda estatal. Em outros termos, a partir do estabelecimento de princípios operativos básicos para conceituar a educação, Kant também forjou as linhas de transmissão de tais princípios em nome de uma pedagogia raciocionada. Eis o nascimento moderno da utopia pedagógica vaticinada em sua "ambição desmesurada de subjugar o mundo diverso", nos termos de Schérer (2009, p.25).

Ora, mas nem o idealismo essencial rousseauniano e tampouco o idealismo pedagógico racional kantiano circularam livremente no espaço histórico-social do século XVIII. Com a publicação de $O$ Panóptico do filósofo utilitarista inglês Bentham, em 1791, as demandas pela aplicação de princípios arquitetônicos funcionais à economia do Estado passaram a ser tomados como dispositivo-chave na composição de edifícios a favorecer condições de vigilância, de circulação, de controle e de submissão de seus indivíduos, a fim

\begin{tabular}{|c|c|}
\hline - Educacão Temática Diqital & Comni \\
\hline
\end{tabular}


de extrair deles o máximo de produtividade e de eficiência. Estamos às vésperas das condições históricas da explosão da educação em massa (CARVALHO, 2016; ENGUITA, 1989). Na utopia de Bentham, colocar os indivíduos nos seus devidos lugares implica uma economia de ação sobre eles. Vigiá-los sem saber que são vigiados; produzir neles e com eles um comportamento previsível e automatizado; registrar tudo e manter a ordem dos registros; fracionar tempo e espaço para racionalizar as ações e as expectativas de comportamentos individuais; extrair o máximo de energia dos corpos com o mínimo de dispêndio possível (BENTHAM, 2008; FOUCAULT, 1991). Tais elementos efetivaram-se com força incontornável na máquina escolar, melhor ainda, no dispositivo pedagógico. Da prisão à fábrica, do hospital à escola, do quartel às organizações dos fluxos pulsantes das cidades, “a utopia pedagógica é e permanece, no seu fundo, 'panóptica'” (SCHÉRER, 2009 p.34). O Panóptico de Bentham pode ser tomado como o ponto de partida da inventividade moderna do desejo de tecnocracia presente no dispositivo pedagógico, isto é, na máquina de poder da escola.

Esse cenário todo nos auxilia a compreender a proveniência de um tríplice fundamento filosófico do dispositivo pedagógico, cuja força se faz ver na escola contemporânea e como, aos poucos, ela se fixou como aparelho coletivo de formação perversa. Em primeiro lugar, implica dizer que uma série de representações, ainda eivadas por certos essencialismos, tal como inaugurou Rousseau, permanece no dispositivo escolar. Ainda se busca a essência da educação, a idealização de uma "boa" formação, capaz de contemplar todos os aspectos do indivíduo a ser formado. Este, por sua vez, é a representação máxima de uma natureza congelada na reprodução de um corpo social arredio às diferenças e às multiplicidades capazes de se afirmarem para além da estatização da subjetividade.

Todavia, em segundo lugar, todo jogo de representação idealista do dispositivo pedagógico se amplifica pelos processos de racionalização escolar. Kant lançou os seus pressupostos básicos: é preciso ter controle das atividades pedagógicas que visem a instrução de modelagem suficientemente capaz de fazer o Estado funcionar bem. Não é qualquer conteúdo que pode ser abordado nas intenções conjugadas entre escola e burocracia estatal, pois a máquina de poder não pode estar à deriva: merece todo o tipo de controle, a começar pelos princípios racionais que devem se tornar válidos para a educação universalmente. Afinal de contas, não era inconsequente a utopia kantiana: "um projeto educativo deve ser executado de modo cosmopolita" (KANT, 2011, p.22), isto é, sob a égide de uma racionalização omnes et singulatim voltada para o governo geral dos homens, a partir de suas individualidades. Desde então, qualquer tipo de experiência possível com a educação fora das estratégias de captura racionalizadas pelo Estado torna-se uma ameaça a ser combatida pelas próprias regras do Estado. 
Finalmente, a coincidência da máquina de poder com o dispositivo pedagógico desvela-se na lógica do próprio ambiente escolar. Ambiente de múltiplo controle tempoespacial pensado por Bentham e reduplicado nas inúmeras estratégias tecnocráticas da escola. A educação moderna, com efeito, é uma arquitetura complexa de modelagem social no sentido de saber direcionar os fluxos potentes de seus sujeitos à demanda conceitual pressuposta em representações dadas e em racionalizações aplicadas. Mau encontro da escola, historicamente, com os essencialismos, os racionalismos e as tecnocracias organizadores de seu dispositivo escolar. Mau encontro inexplicável, como argumentou Clastres (2014), porque a história da escola, de frágil e de contingente contornos, bem que poderia ser outra. Mas a escola, com tais características de sua máquina de poder não assumiu outra face e, para além de bem e de mal, também foi "esse irracional acontecimento" (CLASTRES, 2014, p.149) atrelado à especialização do Estado como máquina representacional, racionalizada e tecnocrática ${ }^{7}$.

Ora, enquanto a reduplicação do que poderíamos chamar de condições universais da máquina de poder da escola ocidental se unificava com a própria representação, racionalização e tecnocracia do Estado, consolidando "a" escola como grande instituição de modelagem social, a propagação e a disseminação de seus propósitos passaram também a serem aferidos de maneira particularizada em cada experiência de escola. Do todo ao particular, ou seja, da ideia da escola, dos princípios universais de formação do homem, das condições de um ambiente controlado, cada escola passou a atuar numa espécie de célula responsável pela constituição do grande tecido escolar, duplamente lócus e modus operandi do dispositivo pedagógico. A noção de equipamento coletivo, extraída do pensamento de Guattari $(2005,2011,2013)$, auxilia-nos nesta compreensão.

O equipamento coletivo diz respeito à associação de seus integrantes regidos por automatismos de suas ações, por repetições de padrões de seus comportamentos, por ideais rígidos e fixados em representações normativas legais ou científicas que se tornam axiomas justificadores das dinâmicas hierárquicas e de todas as divisões pré-estabelecidas sob o influxo de regras burocráticas acéfalas. O equipamento coletivo é uma usina de modelagem subjetiva e, por estar amplamente presente no extenso corpo social, também uma usina de modelagem social. Pensar em modelagem implica dizer que em cada equipamento coletivo existem muitas máquinas de poder funcionando, mas todas elas replicando as suas representações, os seus racionalismos justificadores de ações e de

\footnotetext{
${ }^{7}$ Eis o contexto da expressão de Clastres: "Mais que qualquer outro clarividente, ele [La Boétie] afirma em primeiro lugar que foi sem necessidade essa passagem da liberdade à servidão, ele afirma acidental - e que trabalho a partir de então para pensar o impensável mau encontro! - a divisão da sociedade entre os que mandam e os que obedecem. O que é aqui designado é exatamente esse momento histórico do nascimento da História, essa ruptura fatal que jamais deveria ter se produzido, esse irracional acontecimento ao qual nós, modernos, chamamos, de maneira semelhante, de nascimento do Estado". (CLASTRES, 2014, p.148-149).
} 
comportamentos, e também a sua gama de tecnocracia. Ora, como evidenciou Guattari (2011, p.77),

Os Equipamentos Coletivos não são apenas os muros, os escritórios, as circulações, as transmissões de ordens e de informações, mas também, e acima de tudo, uma modelagem de atitudes, de rituais de submissão impostos por meio de múltiplos componentes semióticos.

Uma escola qualquer, por exemplo, é um equipamento coletivo pois, a seu modo, opera os elementos próprios de como modela os seus sujeitos conforme o jogo de forças e de ação do seu coletivo. Enquanto máquina maior, a escola se faz um equipamento coletivo acoplado às máquinas menores do equipamento coletivo: as posturas dos professores no coletivo de um conselho de classe não são as mesmas no coletivo dos professores no intervalo, nem quando eles se voltam para uma demanda burocrática específica na escola. Como equipamento coletivo, a escola possui o seu coletivo de servidores da manutenção, da administração; coletivo de alunos, sub-coletivizados conforme os ideais e as representações expectadas para eles: bons e maus alunos, os obedientes e os desobedientes, os bons aprendizes ou os incapazes.

Assim, no âmbito do equipamento coletivo, a escola produz um encontro de eficaz adesão institucional à utopia pedagógica perversa, "utopia sempre coercitiva", haveria de mencionar Schérer (2009, p.25). E como ocorre em toda coerção, é a divisão binária entre obedientes e desobedientes que passa a remarcar os "equipamentos coletivos que esperam uma certa adaptação normalizadora" (GUATTARI; ROLNIK, 2005, p.336) de seus sujeitos, a fim de desempenhar a sua função precípua: a territorialização da modelagem social, como argumenta Guattari (2011, p.58-59),

\footnotetext{
empreendendo a possessão dos indivíduos até na suas intimidades, tendo por missão expropriar o desejo de suas territorialidades 'de origem', digamos de suas territorialidades ainda não assujeitadas pelos fluxos capitalísticos, para fazer falar em seu lugar, fixar para o desejo novos alvos, colocá-lo para trabalhar, adaptandoo às hierarquias e aos sistemas de trocas [...]. Por isto mesmo, os equipamentos coletivos conduzem à alienação irreversível da economia do desejo.
}

Em larga medida, a utopia de captura da infância desde Rousseau, Kant e Bentham funcionou muito bem na organização da escola como equipamento coletivo. Vastas operações da máquina de poder passaram a escoltar a infância, premunindo-a "contra todo tipo de intrusão de acontecimentos suscetíveis de desorganizá-la ou de colocá-la em apuros" (GUATTARI, 2013, p.359). Faz sentido, assim, a exclusão do afeto e do desejo nas experiências educacionais eivadas pelo dispositivo pedagógico. Se pensarmos que, para Guattari, tal como ele indica à Rolnik (GUATTARI; ROLNIK, 2005, p.261), o desejo envolve "todas as formas de vontade de viver, de vontade de criar, de vontade de amar, de vontade de inventar uma outra sociedade, outra percepção do mundo, outros sistemas de valores",

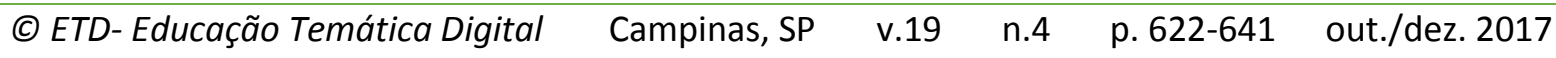


podemos supor o espectro de bloqueio ao desejo criativo e perturbador operado por intermédio do dispositivo pedagógico.

Duas passagens, com farta argumentação de Guattari, auxiliam-nos a esclarecer porque a escola, no registro do equipamento coletivo, lança fora as possibilidades de outras de experiências educativas. E com elas, a inventividade, a criação, a espontaneidade e o afeto não consensual de suas práticas. Em primeiro lugar, porque o sujeito a ser projetado desde a infância é a figura fantasmagórica de um adulto que não existe, mas que deve ser realizado ab ovo. Como já sabemos, devemos tal peripécia a Rousseau e a Kant, e atingimos as suas condições técnicas com Bentham. Sendo assim, a infância deve ser modelada pelos equipamentos coletivos, e não apenas a escola, a fim de assegurar a autorrealização de sua passagem perfeitamente normal para a sociedade interposta à criança.

Se a impregnação aos modelos imaginários, perceptivos, sociais, culturais, etc... não é bem sucedido em fases precoces, ter-se-á enorme dificuldade para modelar os indivíduos às tarefas que lhes serão confiadas nos sistemas altamente diferenciados da produção. Não se enviam as crianças, pelo menos na França, para as manufaturas, na idade de 6 ou 8 anos, além do que se tem a impressão de ter humanizado a escola e as relações familiares. Mas simplesmente trocou-se a roupa da velha crueldade da iniciação que consiste em extirpar da criança, o mais cedo possível, sua capacidade específica de expressão e em adaptá-la, o mais cedo possível, aos valores, significações e comportamentos dominantes (GUATTARI, 1985, p. 53).

Em segundo lugar, porém, porque a escola, por ser equipamento coletivo, não abre mão de exercer a própria função do equipamento coletivo. Talvez seja por isto que o dispositivo pedagógico a tudo pedagogiza, pois mesmo fora da escola não deixamos de nos relacionar com os equipamentos coletivos. E sob tal aposta, aclimatar as considerações de Guattari (2013, p.359) acerca da subjetividade capitalística para a escola, é algo devastador:

Para ela [a escola], toda singularidade ou deverá ser evitada, ou deverá passar debaixo dos equipamentos, dos profissionais e dos quadros de referências especializados. É assim que ela irá até tentar administrar o que é da ordem da descoberta e da invenção do mundo pela infância, pela arte ou pelo amor, bem como o que se relaciona com a angústia, com a dor, com a morte, com o sentimento de estar perdido no cosmos. Por agregação aos afetos consensuais ligados à raça, à nação, ao corpo profissional, à competição esportiva, à virilidade dominadora ou ao sucesso idealizado, a subjetividade se desliza, anestesia-se em um sentimento de pseudo-eternidade. 
Em defesa da escola: o lugar do experimentum scholae na busca de outro equipamento coletivo

Sob tal horizonte, se é preciso defender a escola, é contra o dispositivo pedagógico que temos de defendê-la, dispositivo que a conformou tal como ela se apresenta para nós. Uma resistência da escola em relação ao dispositivo pedagógico, que permita que a escola seja outra, assim, precisa ser pensada. Tal defesa impõe algumas interrogações: como produzir a escola na contramão do dispositivo pedagógico? Que jogos podem ser colocados em prática no tabuleiro da "máquina de poder pedagógico", de modo que a escola possa cacifar uma espécie de "reversão" ou mesmo de "perversão" de sua conformação moderna ao dispositivo pedagógico perverso? Quais os caminhos possíveis para a escola contemporânea?

Pensamos ser imprescindível que a escola saia de sua pseudo-eternidade. 0 dispositivo pedagógico reduz todas as potencialidades dos afetos e das expressões de desejo, que poderiam estar presentes desde as relações humanas na escola, a operações reprodutoras de comportamentos modelados à conformidade institucional. A sensação de que não há saída para a escola é um arranjo consequente desta conjuntura. O que esquecemos, contudo, é que o automatismo profetizado pela tecnocracia benthamiana é mais funcional do que supomos. A fórmula de Thoureau (2012, p.32), neste sentido, bem que poderia ser aplicada a todos aqueles que compõem o equipamento coletivo da escola: "Estadistas e legisladores, estando tão completamente entranhados na instituição, nunca conseguem observá-la de modo distinto e franco". Ora, a pseudo-eternidade da escola se mantém na proporção de nossas desculpas acerca dos automatismos com os quais nela nos habituamos e com os quais na escola estamos entranhados.

Defender a escola de sua pseudo-eternidade, consiste não apenas lutar contra os essencialismos, as racionalizações burocráticas e as engrenagens tecnocráticas nela presentes. Mas partir do diagnóstico que tais características são históricas e que, portanto, podem ser diferentes do que são. Ou ainda, mostrar que o dispositivo pedagógico possui uma fragilidade porque ele pode ser contestado historicamente, ou seja, por sujeitos ativos e concretos, capazes de observar a escola e de nela agir de modo distinto e franco.

É nesta direção que julgamos potente a ideia de experimentum scholae apresentada Masschelein e Simons (2013) em Em defesa da escola. Experimentar a escola e fazer da escola um experimento são relações indissociáveis na produção de um outro equipamento coletivo. A cultura do cotidiano escolar, padecida pelos afetos de pseudo-eternidade, mina lentamente as ações que poderiam mobilizar os seus sujeitos a pensarem de modo diferente, a quererem se relacionar pelos fluxos de afetos sensíveis mais próximos às singularidades e às multiplicidades humanas, a indagar o conhecimento fora do eixo das

\begin{tabular}{|c|c|}
\hline - Educacão Temática Diqital & Comni \\
\hline
\end{tabular}


verdades meramente aplicadas e lucrativas, e, não menos importante, a produzir condições para que a vida pudesse se afirmar pela via do desejo.

Neste caso, implicaria conceber, de fato, que "nenhuma sociedade pode suportar uma posição de desejo verdadeiro sem que suas estruturas de exploração, de sujeição e de hierarquia sejam comprometidas" (DELEUZE; GUATTARI, 2010, p.158). Assim, fazer da escola um campo histórico de experimentum scholae consiste em considerá-la como um laboratório, lugar de constante ensaio e experimentação, no qual processos de criação e de produção de novos manejos com o saber, o conhecimento, as relações subjetivas e intersubjetivas de seus sujeitos encontrem sentido na explosão das estruturas de exploração, de sujeição e de hierarquia tão presentes nos equipamentos coletivos.

A angústia deve fazer parte desse processo. Angústia como território existencial, capaz de nos convocar a sentir a iminência de um devir para o qual precisamos decidir, agir, produzir e nos mobilizar. Mas que também aponta para a abertura possível das ações, para tudo que ainda está por ser feito e realizado, precisamente porque nada está completo e acabado. Deste ponto de vista, a função do equipamento coletivo pode ser outra, distinta das finalidades de modelização social e dos sequestros dos afetos e dos desejos. Para tanto, o equipamento coletivo tem de passar a coincidir com a intensidade de tudo que ousa se firmar como experimentum scholae. ${ }^{8}$

Ora, desde o século XVIII um acúmulo de suposições acerca da escola nos conduziu a reproduzir as condições de manutenção de sua pseudo-eternidade. Defender a escola, neste sentido, é defendê-la dela mesma, ou seja, da condição vital que tem feito da escola o que não desejamos para a escola: o dispositivo pedagógico perverso. Entre a sua composição como equipamento coletivo e a possibilidade de fazer da escola um experimentum scholae reside um axioma político que nada mais é do que a nossa opção pelos valores que desejamos destinar às condições próprias para que a escola experimente a si mesma de outra maneira, com outras condições, com outras relações subjetivas, com conexões estranhas à maquinaria de poder de neutralização e de impotenciação dos afetos e dos desejos. ${ }^{9}$

Se em larga escala o dispositivo pedagógico fez da escola uma máquina de poder capaz de produzir todo tipo de perversão com relação a infância, aos afetos, ao campo do

\footnotetext{
${ }^{8}$ Um experimentum scholae que nos parece interessante pode ser encontrado nos movimentos de ocupação de escolas públicas no estado de São Paulo ao final de 2015, que se alastrou por vários estados brasileiros em 2016. Como não temos condições de desenvolver o tema aqui, tomamos a liberdade de remeter o leitor para um outro artigo nosso: Gallo; Carvalho, 2016.

9 Apenas a título de observação, a ser desenvolvida em outra oportunidade ou a municiar os leitores interessados na questão: pensar a escola como experimentum scholae, como um outro equipamento coletivo, também pode ser potencializado com o conceito foucaultiano de heterotopia (ver Foucault 2001, 2009).
} 
desejo e da criação, defender a escola desse dispositivo nos convida a um amplo conjunto de criação que está por ser feita. A nossa angústia, assim, é o descompasso entre a nossa suposição na pseudo-eternidade da escola - nas coisas como estão e são - e a potência de nosso desejo em querer romper com esta pseudo-eternidade, cientes de que não existe nem receita, nem fórmulas e nem seguranças, apenas, porém, experimentum scholae. Para tanto, interessa não perder de vista que o jogo vital é: "produzir algo que não exista, produzir uma singularidade própria na existência das coisas, dos pensamentos e das sensibilidades" (GUATTARI; ROLNIK, 2005, p.213). Não para replicar máquinas de poder, não para decalcar sobre a escola uma essência da escola, uma razão escolar ou uma configuração espaço-temporal idêntica para a escola. O manejo do devir-outra-escola não deve perder de vista a regra concreta da própria singularidade escolar: "não existe duas instituições semelhantes e que a mesma instituição não cessa de evoluir ao longo do tempo" (GUATTARI, 2012, p.84).

No lugar de um dispositivo pedagógico, um fazer pedagógico experimentado na singularidade de cada escola. No lugar de um equipamento coletivo modelador e reprodutor da hierarquia, da sujeição, do controle, um equipamento coletivo de desejo. No lugar de uma escola congelada em representações pseudo-eternas, um experimentum scholae $^{10}$.

\section{REFERÊNCIAS ${ }^{i}$}

BENTHAM, Jeremy. O panóptico. 2. ed. Belo Horizonte, MG: Autêntica, 2008.

CARVALHO, Alexandre Filordi de. Sociedade capitalista e produção disciplinar excludente: a atualidade de Vigiar e Punir na compreensão da função-sujeito contemporânea. In. CARVALHO, Alexandre Filordi de; GALLO, Silvio (Org.). Repensar a educação - 40 anos após Vigiar e Punir. São Paulo, SP: Editora Livraria da Física, 2015, p. 175-207.

CLASTRES, Pierre. Arqueologia da violência. 3. ed. São Paulo, SP: CosacNaify, 2014

DELEUZE, Gilles; GUATTARI, Félix. O Anti-Édipo: capitalismo e esquizofrenia. São Paulo: Ed. 34, 2010.

ENGUITA, Mariano F. A face oculta da escola: educação e trabalho no capitalismo. Porto Alegre, RS: 1989.

FOUCAULT, Michel. História da sexualidade - 1: a vontade de saber. 6a ed. Rio de Janeiro: Graal, 1985.

\footnotetext{
${ }^{10}$ Este texto compõe parte das pesquisas do projeto o Filosofia das diferenças, transversão epistemológica e o devir-outro na educação, sob financiamento da Coordenação de Aperfeiçoamento de Pessoal de Nível de PósGraduação (CAPES - Processo 8881.11947/2016-01) e da Fundação de Amparo à Pesquisa do Estado de São Paulo (FAPESP - Processo 16/05440-7).
}

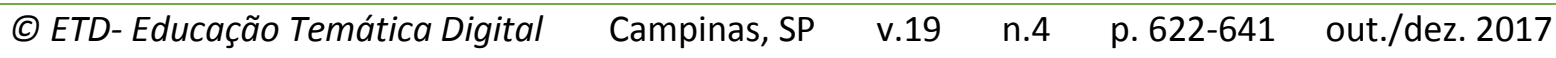


FOUCAULT, Michel. Vigiar e punir - história da violência nas prisões. $8^{a}$ ed. Petrópolis, RJ: Vozes, 1991.

FOUCAULT, Michel. Outros espaços. In: Ditos e escritos, vol. III. Rio de Janeiro, RJ: Forense Universitária, 2001, p. 411-422.

FOUCAULT, M. Le corps utopique, les hétérotopies. Paris: Lignes, 2009.

FOUCAULT, Michel. O jogo de Michel Foucault. In: Ditos e escritos, vol. IX. Rio de Janeiro, RJ: Forense Universitária, 2014. p. 44-77.

GALLO, Sílvio. Pensar a escola com Foucault: além da sombra da vigilância In: CARVALHO, Alexandre Filordi de; GALLO, Silvio (Org.). Repensar a educação - 40 anos após Vigiar $e$ Punir. São Paulo, SP: Livraria da Física, 2015. p. 427-449.

GALLO, Sílvio; CARVALHO, Alexandre Filordi de. Des lycéens se constituent en "groupe sujet» - et réinventent une confiance politique. Revue Internationale d'Éducation Sèvres, n. 72, 2016. p. 137-146

GÉLIS, Jacques. A individuação da criança. In. História da vida privada: da Renascença ao Século das Luzes. São Paulo, SP: Companhia das Letras, 2009. p. 305-320

GUATTARI, Félix. Revolução molecular: pulsações políticas do desejo. Tradução de Suely Rolnik. 3. ed. São Paulo, SP: Brasiliense, 1985.

GUATTARI, Félix. Lignes de fuite: pour un autre monde de possibles. La Tours d'Aigues: L'aube, 2011.

GUATTARI, Félix. De Leros à la Borde. Clamecy: Lignes/IMEC, 2012.

GUATTARI, Félix. Qu'est-ce que l'écosophie? Clamecy: Lignes/IMEC, 2013.

GUATTARI, Félix; ROLNIK, Suely. Micropolíticas: cartografias do desejo. 7. ed. Petrópolis, RJ: Vozes, 2005.

HILSDORF, Maria Lúcia Spedo. 0 aparecimento da escola moderna - uma história ilustrada. Belo Horizonte, MG: Autêntica, 2006.

ILLICH, Ivan. Sociedade sem escolas. 6.ed. Petrópolis, RJ: Vozes, 1982.

KANT, Imannuel. Sobre a pedagogia. 6.ed. Piracicaba, SP: Unimep, 2011.

MASSCHELEIN, Jan; SIMONS, Maarten. Em defesa da escola - uma questão pública. Belo Horizonte, MG: Autêntica, 2013.

NIETZSCHE, Friedrich. Escritos sobre educação. Rio de Janeiro, RJ: PUC Rio/São Paulo: Loyola, 2003.

RANCIÈRE, Jacques. O mestre ignorante. Belo Horizonte, MG: Autêntica, 2002.

ROUSSEAU, Jean-Jacques. Emílio ou da educação. Rio de Janeiro, RJ: Bertand Brasil, 1992.

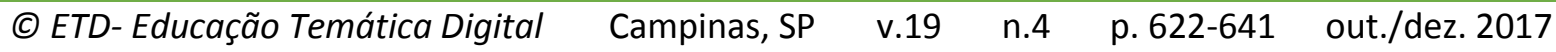




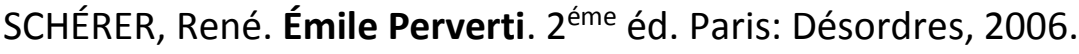

SCHÉRER, René. Infantis. Belo Horizonte, MG: Autêntica, 2009.

SCHÉRER, René; HOCQUENGHEM, Guy. "Co-Ire": álbum systématique de l'enfance. Recherches no 22. $2^{\mathrm{e}}$ éd, Avril 1977.

SCHÉRER, René; LAGASNERIE, Geoffroy de. Après tout - entretiens sur une vie intellectuelle. Paris: Éd. Cartouche, 2007.

THOUREAU, Henry David. A desobediência civil. São Paulo, SP: Companhia das Letras \& Penguin, 2012.

\footnotetext{
' Revisão gramatical do texto sob a responsabilidade dos autores
} 